\title{
Biomédica Instituto Nacional de Salud
}

Volumen 25, No. 2 - Bogotá, D. C., Colombia - Junio, 2005

\section{Editorial}

\section{El derecho a morir con dignidad}

En las más diversas culturas de los cinco continentes, puede identificarse el concepto de "muerte digna" desde muy remota antigüedad. Parece que el ser humano, en el pasado prehistórico y como parte de la elaboración del concepto global de muerte, concibió algunas formas de ese fenómeno como distintas de las que se observaban en otros seres vivos y en cambio, más acordes con lo esperado y deseable para él mismo y para sus semejantes. Las ceremonias para disposición del cadáver, como la sepultura entre pétalos de flores y rodeado por armas y utensilios, pudieron ser muestras de esa actitud; se consideró en cambio durísimo castigo la muerte en condiciones de indignidad. Los mayas y aztecas mesoamericanos tenían claro que la suerte del individuo en el inframundo - lugar de los muertos estaba relacionada, más que con la forma en que se hubiera vivido, con la manera como se hubiera llegado a la muerte.

Pero en los decenios finales del pasado siglo $X X$, a consecuencia de los inmensos avances en el conocimiento y los consiguientes progresos tecnológicos, apareció una visión nueva de la muerte como situación susceptible de intervenciones capaces de retardarla verdaderamente y quizá, para los más optimistas, de impedirla y hacer realidad el milenario sueño de la inmortalidad para los seres humanos. Las Unidades de Cuidados Intensivos abrieron la posibilidad de recuperar para la sociedad muchas personas que, por heridas $u$ otras lesiones, hubieran estado antes condenadas a pronta muerte. Y se inició también la preocupación ética y bioética por aquellos casos en los que ciencia y tecnología detienen transitoriamente el proceso de terminación de la vida pero sin lograr que el individuo quede restaurado por completo en sus funciones intelecturales ni recupere la capacidad para relacionarse consigo mismo y con cuanto lo rodea; a tal condición fisiopatológica se la ha llamado estado vegetativo persistente.

Aceptado en el mundo occidental el marco ético que reconoce a la persona humana como sujeto de derechos que le pertenecen por razón de su esencia y que deben respetarse, entre los cuales se halla el derecho a la autonomía -entendida como capacidad para resolver libremente sobre todo aquello que la afecte de cualquier modo- parece apenas lógico pedir y esperar que se permita el ejercicio pleno de esa autonomía en todas las etapas de la vida, sin más limitaciones que aquellas que pueda imponer la situación mental del individuo; esto incluye, sin duda, la etapa final o "terminal" mientras en ella se conserve la conciencia.

La muerte digna será, en ese contexto, la que llegue en las condiciones que elija quien va a morir; tal elección deberá poderse hacer cuando se inicien esos "últimos días" pero también debe ser posible en forma de voluntad anticipada, de "testamento vital" que la persona ponga por escrito con determinadas formalidades cuando aún esté lejos de su fin y que, conocido por sus parientes y por los profesionales encargados de atenderlo, sea de obligatorio cumplimiento aunque el firmante haya perdido la capacidad mental para exigirlo.

El respeto a los documentos de voluntad anticipada, que en Colombia se llaman "Esta es mi voluntad", exije del médico la humildad suficiente para renunciar a su situación privilegiada frente al enfermo y sujetarse a lo que éste haya decidido, aunque al profesional le parezca inadecuado o reñido con sus propios conceptos sobre "santidad de la vida" y otras posturas religiosas. Sin embargo, esa es la actitud realmente más humana porque muestra y pone en acción la visión del "otro" como ser humano 
con las mismas cualidades y digno de igual respeto, a quien la enfermedad no ha despojado de nada distinto de algunas posibilidades o funciones puramente orgánicas. Es también la actitud que se ajusta en nuestro país a las disposiciones legales en las que figuran los derechos de la persona enferma, así como aquellas que regulan el ámbito ético-disciplinario médico (Ley 23 de 1981, principalmente) y las internacionales sobre estas materias.

El compromiso esencial de la Medicina como profesión es con la persona humana; las exhortaciones sobre el cuidado de la vida deben entenderse, por supuesto, como relativos a cuanto tenga vida y también a lo que es necesario para mantener la vida en nuestro planeta, única "nave espacial" con que cuenta nuestra especie para su viaje milenario por el Universo; pero al enfocarlas sobre la vida humana, es necesario ponerlas en el contexto de humanidad para evitar que se interpreten como exigencia de mantener cualquier mínima señal de vida biológica en un cuerpo que ya no albergue ni siquiera en potencia aquello que caracteriza al ser humano, la conciencia.

Consideración aparte necesita el asunto de la eutanasia, vocablo que sigue tan cargado de implicaciones emocionales como para dificultar cualquier discusión al respecto. En este comienzo del siglo XXI, debe entenderse por eutanasia el acto (acción u omisión) realizado con intención de cortar la vida de un ser humano que sufre intolerablemente, a quien no hay otro modo de aliviar sus sufrimientos porque su lesión no tiene tratamiento curativo, y que ha pedido él mismo de manera libre y reiterada que se le de muerte para no seguir sufriendo. En la definición, los puntos claves son la voluntad de dar muerte, la magnitud del sufrimiento y la solicitud por parte de quien va a morir; quien practica eutanasia no se toma la libertad de acabar con una vida humana, sino solamente (porque sus propias convicciones se lo permiten) se ajusta a lo que exige una persona que sufre y que, ella sí, en uso de su autonomía resuelve sobre su propia existencia terrenal, de un modo que seguramente no choca con sus convicciones.

La "muerte digna" no es, no puede ser, solamente la conseguida por eutanasia aunque ésta sí debe estar entre las posibilidades para que la pida y utilice quien considere que puede hacerlo. La "muerte digna" incluye alivio del dolor y de cualquiera otra incomodidad o molestia inherente a la agonía, como lo requiera la persona concreta en sus circunstancias, cariño, compañía y apoyo emocional, ambiente respetuoso -en la casa del moribundo, si éste prefiere, pues la sala de clínica u hospital no suele ofrecer la tranquilidad necesaria-y los auxilios religiosos que la persona desee.

Entendidas de esta manera las posiciones, parece lógico esperar que toda persona en uso de sus facultades mentales desee morir con dignidad y ponga de su parte lo necesario para conseguirlo. La sociedad y el Estado deben dar las condiciones para que la elección individual sea posible y se respete plenamente, como una de las garantías a que tiene derecho el ser humano por la sola razón de existir, como uno de los supuestos básicos para el libre desarrollo de la personalidad, en el mejor sentido de este concepto.

Juan Mendoza Vega, M.D.

Ex presidente, Academia Nacional de Medicina, Bogotá, D. C., Colombia; Profesor Emérito y Catedrático, Colegio Mayor de Nuestra Señora del Rosario, Facultad de Medicina, Bogotá, D. C., Colombia; Presidente, Fundación Pro Derecho a Morir Dignamente, Bogotá, D. C., Colombia; Miembro Fundador, Instituto Colombiano de Estudios Bioéticos, ICEB, Bogotá, D. C., Colombia; ex presidente, Federación Latinoamericana de Neurocirugía, FLANC; ex presidente, Asociación Colombiana de Neurocirugía, Bogotá, D. C., Colombia. 